\title{
Seismic Imaging in Long Valley, California, By Surface and Borehole Techniques: An Investigation of Active Tectonics
}

John B. Rundle1, Greg J. Elbring1, Richard P. Striker1, John T. Finger1, Charles C. Carson1, Marianne C. Walck1, William L. Ellsworth2, David P. Hill2, Peter Malin', Enrique Tono3, Michelle Robertson ${ }^{3}$, Steve Kuhlman3, Tom McEvilly4, Richard Clymer4, Scott B. Smithson5, Sharon Deemer5, Roy Johnson', Tom Henyey6, Egill Hauksson6, Peter Leary6, John McCraney6, Edi Kissling ${ }^{7}$

\section{PAGES 194-200}

\section{Introduction}

The search for silicic magma in the upper crust is converging on the Long Valley Caldera of eastern California, where several lines of geophysical evidence show that an active magma chamber exists at mid- to lower-crustal depths. There are also other strong indications that magma may be present at depths no greater than about $5 \mathrm{~km}$ below the surface. In this paper, we review the history of the search for magma at Long Valley. We also present the preliminary results from a coordinated suite of seismic experiments, conducted by a consortium of institutions in the summer and fall of 1984, that were designed to refine our knowledge of the upper extent of the magma chamber. Major funding for the experiments was provided by the Geothermal Research Program of the U.S. Geological Survey. (USGS) and by the Magma Energy Technology Program of the U.S. Department of Energy (DOE), a program to develop the technology necessary to extract energy directly from crustal magma. Additional funding came from DOE's Office of Basic Energy Sciences and the National Science Foundation (NSF). Also, because extensive use was made of a $0.9-\mathrm{km}$-deep well lent to us by Santa Fe Geothermal, Inc., the project was conducted partly under the auspices of the Continental Scientific Drilling Program (CSDP). As an integrated seismic study of the crust within the caldera that involved the close cooperation of a large number of institutions, the project was moreover viewed as a prototype for future scientific experiments to be conducted under the Program for Array Seismic Studies of the Continental Lithosphere (PASSCAL). The experiment thus represented a unique blend of CSDP and PASSCAL methods, and achieved goals consistent with both programs.

The project was originally conceived at a workshop on seismic imaging in Long Valley, organized by the USGS in April 1984. The purpose of the workshop was to organize an interagency program to explore the Long Valley caldera using seismic techniques, with the goal of constructing a three-dimensional image of the shallow crust. To initiate the program, the USGS committed itself to a limited program of crustal reflection profiling along a line or lines to be determined at the meeting. Previous active seismic experiments included a substantial set of refraction lines throughout the Long Valley area shot by the Geological Survey. Funding for the initial refraction work in 1973 had come from the USGS, while support of the later work during the summers of 1982 and 1983 had come principally from the Office of Basic Energy Sciences at the Department of Energy.

Just before the April workshop, Sandia National Laboratories had obtained permission to reenter a $0.9-\mathrm{km}$-deep abandoned well in Long Valley, which had been drilled by Santa Fe Geothermal, Inc. Designated OLV-1, the well is located in the northwest part of the caldera (Figure la), just above a significant reflector seen by Hill [1976] (Figure $1 b$ ) in the earlier refraction profiling. This reflector was interpreted as the top of a magma body at a depth of $7 \mathrm{~km}$. Together with a group from the University of Southern California (USC), Sandia planned to conduct a passive seismic recording experiment in the well. At the meeting it was decided to use both borehole and surface techniques in a coordinated experiment. Therefore we decided to route the reflection profile by the well site and to perform a vertical seismic profile (VSP) in the well. The VSP complements both the reflection profiling and passive recording by providing the near-surface seismic velocities at the site for use in static corrections and in evaluating receiver structure. We also hoped that the VSP might succeed in observing reflections from the top of the hypothesized magma body at about $7 \mathrm{~km}$ depth.

A second meeting was held at Menlo Park, Calif., in June to coordinate the project, and August 1984 was set as the experiment start date. Sandia was responsible for operating the well. A group from USC was funded by Sandia to deploy a downhole geophone during the VSP and to record earthquakes for about a month from the geophone in the well and from a small surface array. Modeling and analysis of these data is in progress by Sandia and USC. Lawrence Berkeley Laboratory and the University of California, Santa Barbara, fielded the VSP experiment and are reducing the data. Meanwhile, USGS and the University of Wyoming conducted the $P$ wave reflection profile and are providing the final data stacks.

'Sandia National Laboratories, Albuquerque, N.M

2U.S. Geological Survey, Menlo Park, Calif

${ }^{3}$ University of California, Santa Barbara.

${ }^{4}$ Lawrence Berkeley Laboratory, Berkeley, Calif.

${ }^{5}$ University of Wyoming, Laramie.

${ }^{6}$ University of Southern California, Los Angeles. ${ }^{7}$ Eidgenössische Technische Hochschule (ETH), Zürich.
Cover. Cross section through Long Valley caldera in eastern California, showing the geometry of the caldera floor and the underlying magma chamber as inferred from the recent geological, seismological, and geophysical studies described by J. B Rundle et al. ("Seismic Imaging in Long Valley, California, by Surface and Borehole Techniques: An Investigation of Active Tectonics," p. 194). Heavy lines indicate positions of boundaries reflecting seismic $P$ waves that were recorded by re- cent seismic refraction and reflection surveys. Ground deformation (the resurgent dome has inflated by $0.5 \mathrm{~m}$ in the past 5 years) and seismic activity are consistent with increasing pressure within the magma chamber and possible injection of a thin dike (or dikes) into the ring fracture system beneath the south moat, where the earthquake swarm activity (as indicated by the stars) has been most intense. Cross section prepared by R. A. Bailey and D. P. Hill, U.S. Geological Survey. Current work in Long Valley will be discussed in four sessions at the 1985 AGU Spring Meeting: Lithospheric Studies With Long Arrays I (PASSCAL Symposium) (Tuesday, May 28, 8:15 A.M.), Lithospheric Studies With Long Arrays II (PASSCAL Symposium) (Tuesday, May 28, 2:00 P.M.), Inyo Domes Drilling I (Monday, May 27, 8:30 A.M.), and Inyo Domes Drilling II (Monday, May 27, 1:30 P.M.). 


\section{Background}

In a U.S. Geological Survey refraction experiment conducted in 1973, Hill [1976] shot two intersecting seismic refraction lines across the caldera. One of these lines extended 35 $\mathrm{km}$ east-southeast from the northeast boundary of the caldera across the resurgent dome to the southeast boundary of the caldera. On it, he observed a phase about $1 \mathrm{~s}$ behind the first arrival from the shot point near Deadman Creek. In a subsequenc study, Hill et al. [1985] shot seven reversed profiles across the caldera, one of which extended from the north central boundary (B, Figure $1 b$ ) to the southwest boundary (A) at Minaret summit. At offset distances of $14-20 \mathrm{~km}$ from the northeast end (B) of this line, an arrival was observed that was again interpreted to be a reflection off the top of the same magma body under the northern end of the resurgent dome. Hence both refraction lines have evidently seen the same reflector in the same location.

In addition to the refraction profiling conducted in Long Valley, Sanders [1984] has conducted a systematic study of shear wave extinction in seismic waves passing through the caldera. Most of the stations that he used are to the north and east, and most of the earthquakes were in the.south moat of the caldera and further south into the Sierran

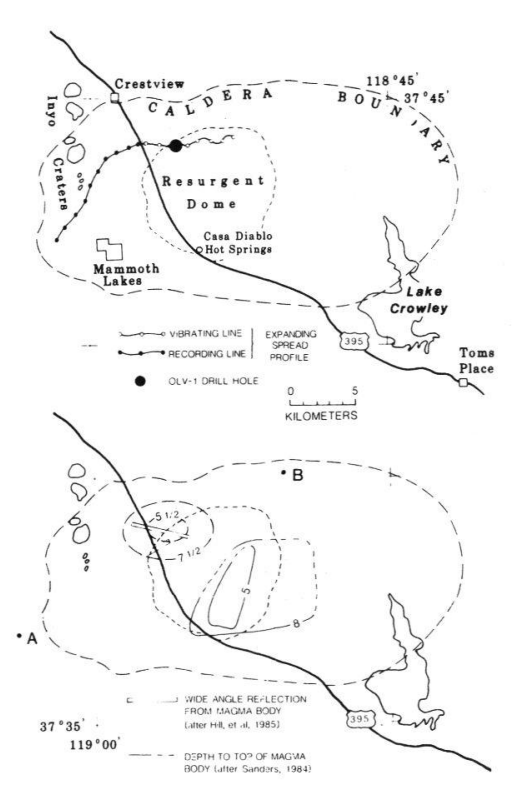

Fig. 1. Long Valley caldera of eastern California. (top) Location of 1984 experiments across the northwestern margin of the resurgent dome. University of Wyoming conducted a vertical incidence to wide-angle reflection survey along the profile and a standard vertical incidence reflection profile in the central part. The $0.9-\mathrm{km}$-deep OLV-1 drill hole was used by a variety of institutions, led by Sandia $\mathrm{Na}-$ tional Laboratories, for both active source and passive recording experiments. (bottom) Summary of preexisting knowledge on the depth to suspected magma chamber beneath Long Valley. Leveling profile of Figure 2 follows highway 395 northeast from Toms Place. block. By using a simple graphical scheme, Sanders identified two major bodies of magma within the caldera, one under the southeast part of the resurgent dome and one in the northwest part of the caldera, under the northwest edge of the resurgent dome. The depth of the northern magma appears to be about 5-6 km and that of the southern body seems to be about $4-5 \mathrm{~km}$. The northern body thus is similar in size and location to that found from the refraction data. The southern body is located near the site proposed by Rundle and Whitcomb [1984] for a shallow magma chamber just east of Casa Diablo hot springs, near where uplift measured from $1975-1980$ by surface leveling is a maximum (Figure 2). The 1984 Long Valley crustal imaging experiment was conceived as an attempt to further confirm the existence of both bodies of shallow crustal magma within the caldera.

\section{Northern Cupola: Active Seismic Experiments}

The seismic refraction experiments conducted by D. P. Hill and his colleagues at USGS in 1973 and 1983 across the northwestern margin of the resurgent dome each produced a strong reflection that has been interpreted as the roof of the contemporary magma chamber [Hill, 1976; Hill et al., 1985]. In the 1973 experiment the polarity of the reflection was clearly $180^{\circ}$ out of phase with the first arrival, indicating a velocity decrease across the reflector. More compelling support for magma within the northwestern quadrant of the caldera was found by Sanders [1984] in his study of shear wave attenuation. Although the location and shape of the body could be only approximately determined, because of limited ray path coverage, the ray paths with
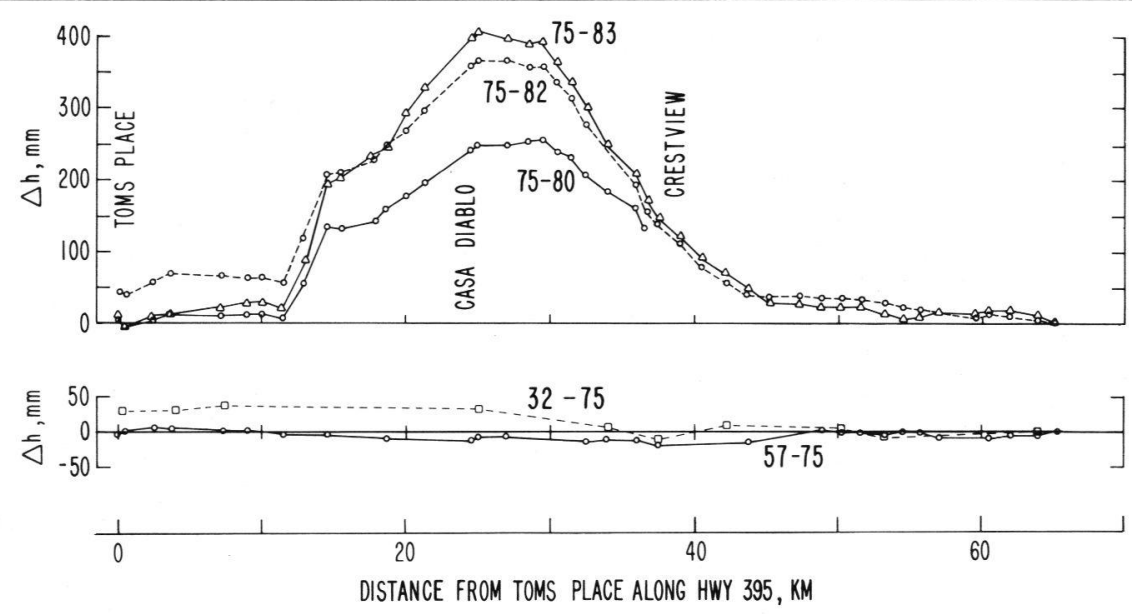

Fig. 2. Elevation changes along highway 395 determined by repeated leveling run during the indicated years with 1975 as the baseline. Tectonic uplift of the resurgent dome of Long Valley caldera began between 1975 and 1980 and continued through at least 1983 (figure after Castle et al. [1984]).

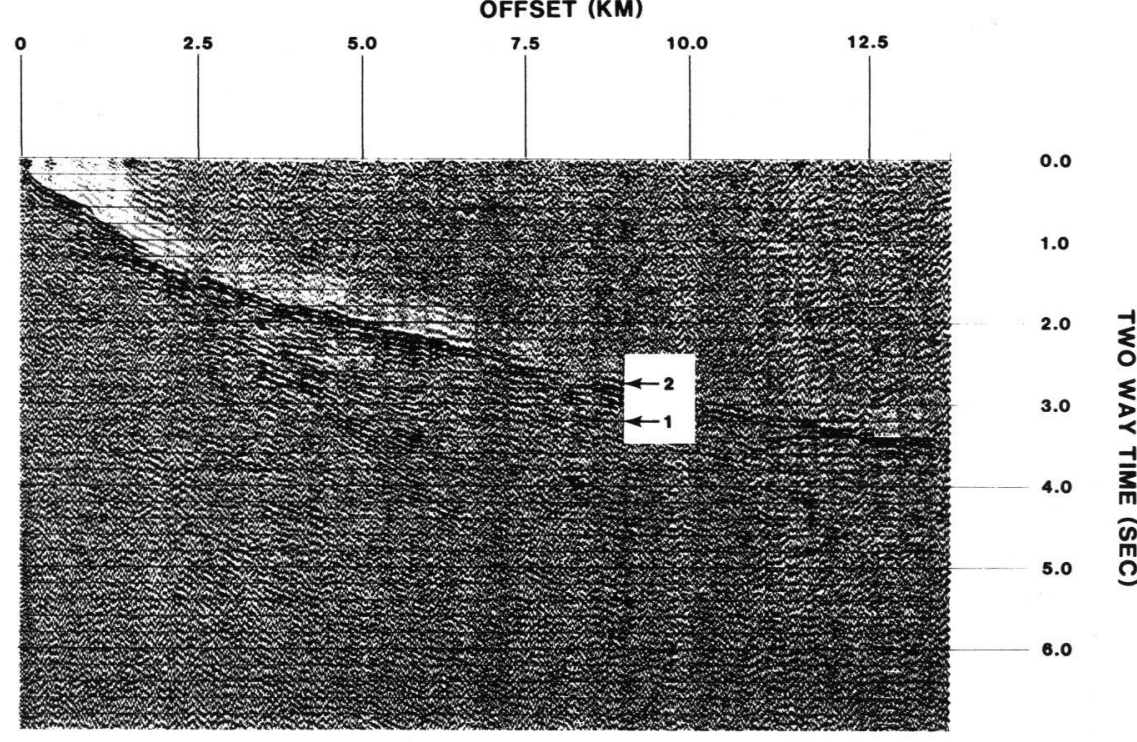

Fig. 3. Single-fold wide angle walk-in $P$ wave reflection profile along route shown in Figure 1 (raw data). Source-receiver offset is in kilometers at top of figure; two-way travel time is in seconds along right margin. Note reflection wavefront (arrow 1) about $0.5 \mathrm{~s}$ behind the refracted first arrival (arrow 2). Automatic gain control has the effect of increasing noise amplitude prior to the arrival of the refracted first phase (arrow 2). Midpoint between source and receiver is fixed at a point just east of highway 395. 
nearly total shear wave extinction cross the northwestern flank of the resurgent dome at about the same depth and location as the reflector described by Hill.

These two independent lines of evidence for magma within about $6-8 \mathrm{~km}$ of the surface were used to design three active seismic experiments conducted in 1984. The experiments were

- an expanding spread (or walk-in) profile about a fixed common midpoint [Deemer et al., 1984];

- conventional common depth point (CDP) seismic reflection profiling [Deemer et al., 1984];

- a vertical seismic profile (VSP) in OLV-1.

Each experiment used standard petroleum exploration industry geophone and recording equipment, as well as vibrators for energy sources. An additional objective of each experiment was the assessment of unproven seismic techniques for use in locating magma

The resurgent dome proved to be an extremely inhospitable environment for seismic recording because of the presence of unconsolidated tephra deposits, either at the surface or interbedded with rhyolite and basalt flows at depth. (One experienced hand was overheard remarking that it was the worst [stuff] that he had ever planted a geophone in.) The poor surface conditions produced three separate experimental problems, including poor coupling between the vibrator trucks and the earth, strong attenuation of seismic waves near the receivers, and highly variable excitation of near-surface multiple reflections at the source. Despite all of these difficulties, preliminary analysis and interpre tation of data from each experiment indicate that each succeeded in recording a reflection from about 7-8 km depth.

The reflection can be seen on the walk-in profile in Figure 3 (arrow 1) as a secondary arrival behind the refracted first arrival (arrow 2 ) in the distance range from at least 5 to $8 \mathrm{~km}$. The common midpoint (CMP) for this single-fold record (about $1 \%$ of the field data) lies just west of highway 395, where the same wide-angle reflection was observed earlier. Thus we successfully duplicated the 1983 refraction experiment, which used large $(1000-\mathrm{kg})$ chemical explosions with industry standard exploration equipment. Because the distribution of CMP's from the full walk-in profile cover an area nearly $1.5 \times 3 \mathrm{~km}$ in size, these data give us true three-dimensional subsurface coverage of the reflector. Further analysis of these data is continuing at the University of Wyoming.

The more conventional approach to defining the configuration of the reflector would be to use CDP recording geometry with nearvertical incidence ray paths. Approximately the central third of the walk-in profile was also recorded as a CDP profile. Preliminary analysis of the CDP profile shows several shallow reflections, probably from the top and bottom of the welded Bishop Tuff, but not the deep reflection. Shot records indicate that source multiples are a persistent-and spatially variable - problem. These shallow reverberations may mask deeper and weaker reflections.

The vertical seismic profile (VSP) run in OLV-1 (Figure 4) clearly demonstrates the dominance of reverberant energy at the sur-

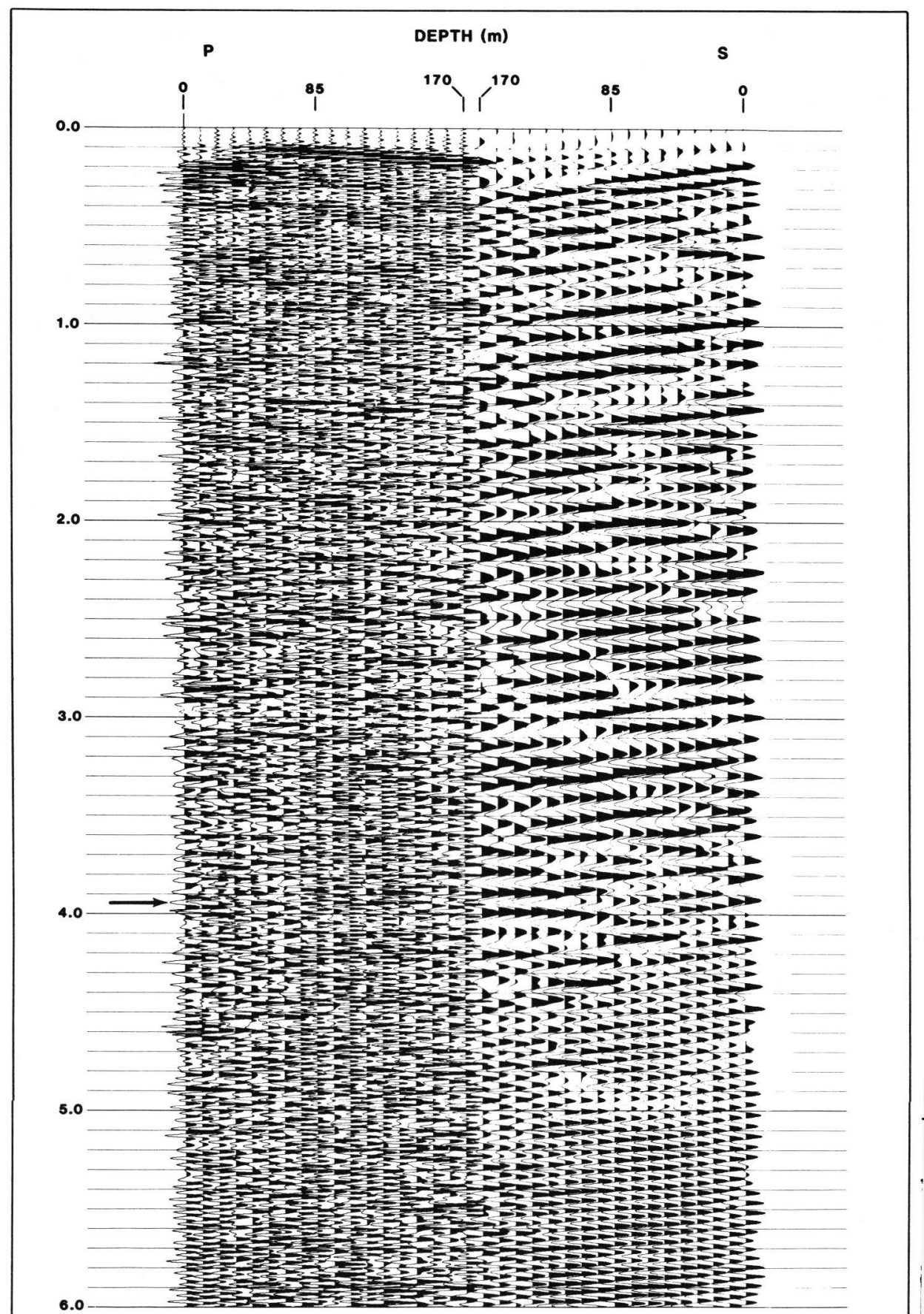

Fig. 4. Vertical seismic profile from upper $170 \mathrm{~m}$ of OLV-1, vertical component only (raw data). Left half of the figure is from $P$ vibrator, right half is from $S$ vibrator. Depth of recording is shown along top of figure; time is along left margin. The $P$ wave recordings were shot as the geophone descended, while the $S$ wave recordings were shot during ascent, so that depth on the $S$ records is reversed left-to-right from the $P$ records. Coherent arrivals across all channels on either $P$ or $S$ records with opposite dip to the downgoing first arrival indicate upcoming reflections from a deep horizon. Note dominance of reverberating arrivals on the records. The most prominent candidate for an upcoming wave appears on the $P$ record at $3.95 \mathrm{~s}$ (arrow).

face. The VSP section (vertical component only) displays the wave field for a single source location at various depths in the well and thus allows us to separate the downgoing wave field from the upcoming (reflected) wave field. Inspection of the $P$ wave VSP (left-hand side of figure) shows that the wave field consists almost entirely of downgoing waves (correlated wavelets arrive at progressively later times at deeper depths). The most promising candidate for a deep reflection occurs at $4.0 \mathrm{~s}$, or from about $10 \mathrm{~km}$ depth. It can be seen as a wavelet with the opposite dip to the first break in Figure 4. If the reflector observed at wide angle is present beneath OLV-1, where it should be seen at about $3 \mathrm{~s}$, it is effectively masked in the VSP.

The 3-s reflector has, however, been tentatively identified, in the stacked shot record from a small array at OLV-1, that is effective- 
ly a single-fold vertical incidence, $P$ wave CDP section. The array consisted of 36 vertical component stations at $30-\mathrm{m}$ intervals stretching due east from the well. About 100 shots have been stacked to produce the record in Figure 5, as opposed to 4-6 shots in the stack of Figure 4. The 4.0-s event seen in the VSP is clear in the CDP section (arrow 1), together with a fainter, less obvious reflection at $3.0 \mathrm{~s}$ (arrow 2). In Figure 6 we summarize the preliminary findings from the active source investigations of the northern cupola The agreement between the wide-angle reflector found by Hill et al. [1985] and the reflection seen on the walk-in profile encourages us to provisionally correlate them with the 3.0-s reflection at OLV-1. If these reflections define the roof of the contemporary magma chamber, as the results of Sanders [1984] would suggest, then the deeper reflection at OLV-1 must arise elsewhere; perhaps from the base of the chamber or from an out-of-plane part of the roof.

\section{Geotomography and Teleseismic Studies}

The broadly dispersed distribution of earthquakes within and around Long Valley caldera provide a nearly ideal data set for three-dimensional modeling of the $P$ wave velocity structure. Kissling et al. [1984] used over $30,000 P$ wave arrival times from 2450 events to determine the velocity structure in $2 \times 2 \times 2-\mathrm{km}$ cells, by using an algorithm modified from Thurber [1983]. In general, their results suggest the presence of a zone of low $P$ wave velocity beneath the southern part of the resurgent dome and the south moat of the caldera between 5 and $9 \mathrm{~km}$ below the surface. This anomaly overlies a weaker and broader zone of low $P$ wave velocity (Figure 7) that extends to a depth of at least $15 \mathrm{~km}$. The broader low-velocity zone extends north from Long Valley toward the Mono Craters and southeast beneath the frontal range of the Sierra Nevada.

The structure of the lower crust and upper mantle beneath Long Valley is also under investigation by the teleseismic travel time residual method. H. M. Iyer and his colleagues at USGS repeated the earlier survey of Steeples and Iyer [1976] this past summer with a greatly expanded array that had an average station spacing of $5 \mathrm{~km}$. Results from the three-dimensional block modeling of teleseis mic $P$ waves from an adjacent array covering the Inyo/Mono Craters by Achauer et al. [1984] resolve a small, low-velocity body in the mid-crust directly beneath the Mono Craters chain. Thus there is evidence for partially molten magma chambers beneath both Long Valley caldera and the younger Mono Craters to the north

\section{Southern Cupola: Passive Seismic Experiment}

The objective of the passive seismic borehole experiment is to search for evidence either confirming or rejecting the hypothesis of shallow magma underlying the Casa Diablo hot spring area. Funding for this part of the project was provided primarily by the Magma Energy Technology Program, with a small additional increment from the DOE Office of Basic Energy Sciences. Drilling to open the

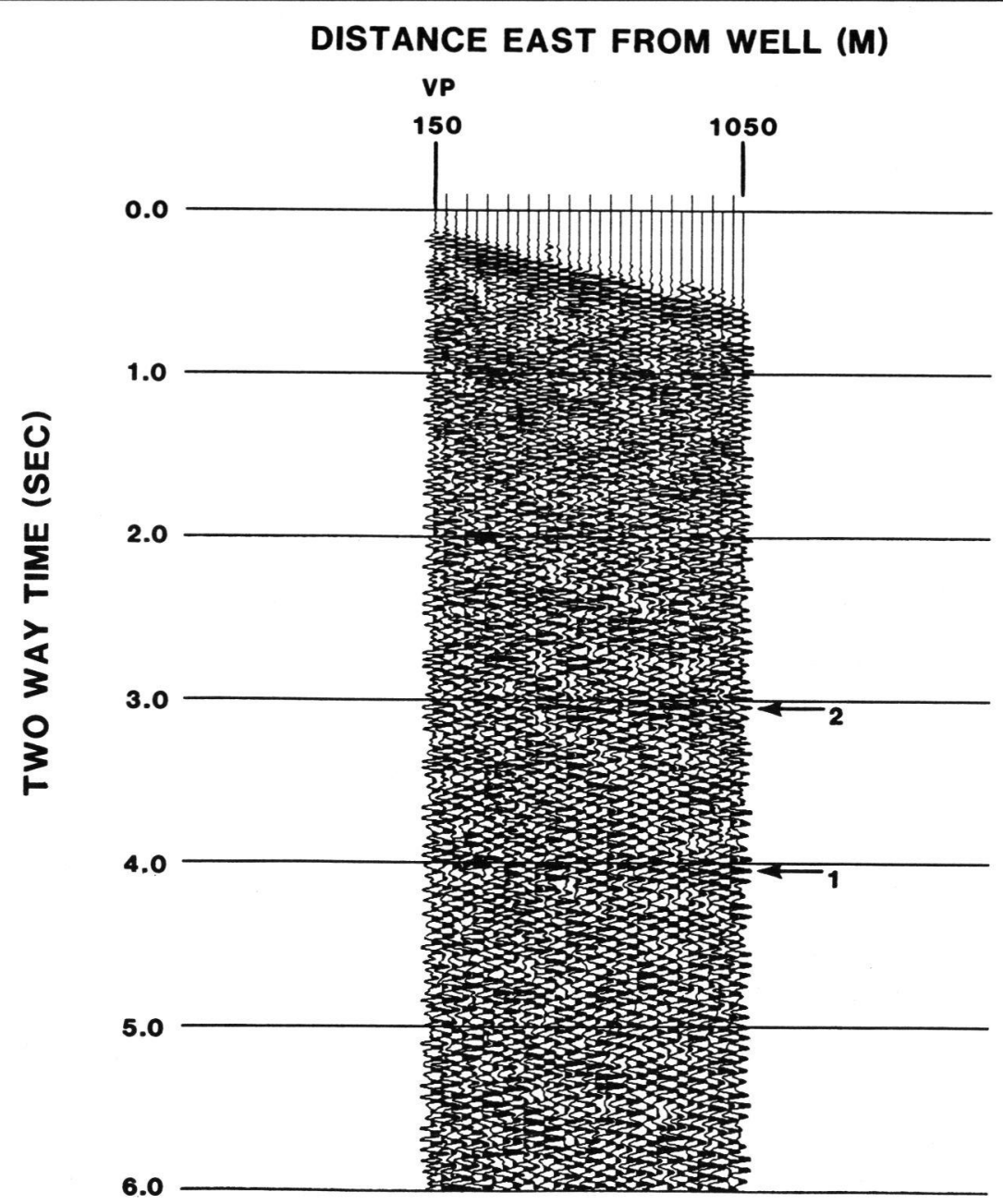

Fig. 5. Small-scale vertical incidence reflection profile at OLV-1 (raw data). The vertical component geophone array stretches east from OLV-1, with station intervals of $30 \mathrm{~m}$. Distance east from OLV-1 is shown along top of figure; two-way travel time is along left margin. $P$ wave record is shown. About 100 shots are stacked to produce the records shown. Note the clear reflection at about 4 seconds (arrow 1) and the somewhat less distinct reflection at 3 seconds (arrow 2).

well commenced on September 7, 1984, and was completed by September 13. The upper $152 \mathrm{~m}$ of the well was cased, with an inside diameter of $0.164 \mathrm{~m}$ and with a drift diameter (of the threaded couplings) of $0.161 \mathrm{~m}$. Below the casing, the open hole diameter was nominally $0.152 \mathrm{~m}$. Upon completion of drilling, the well was caliper logged and was found to have a partial obstruction at about $275 \mathrm{~m}$ depth. The obstruction narrowed the diameter of the well down to about $0.127 \mathrm{~m}$ from the nominal diameter of $0.152 \mathrm{~m}$.

The passive experiment involved emplacement of a borehole geophone at the bottom of the well for a period of at least 1 month. Earthquakes in the south moat of the caldera and into the Sierran block further south were recorded by both the geophone and a surface array provided by USC. Output of the geophone and the surface instruments was recorded on portable digital recorders owned by USC. Transducers in the geophone had an $8-\mathrm{Hz}$ natural period and $395-\mathrm{ohm}$ resistance. Although the period of the instrument is somewhat higher than is desirable for the experiment, this sensor allows borehole deviations in excess of $10^{\circ}$ from vertical, a neces- sary property, since the deviation was unknown prior to the experiment. The geophone clamp is driven by a high-temperature motor on the instrument package and consists of three pressure clamps spaced $120^{\circ}$ apart around the circumference of the instrument to hold it in the center of the well.

The partial obstruction and the clamping mechanism both created problems for the VSP, although the passive experiment was unaffected. The clamps were designed with a travel of only $6.5 \mathrm{~mm}$, so the diameter of the clamping mechanism was nearly equal to the diameter of the well, $0.15 \mathrm{~m}$. With the clamps on, the downhole geophone was unable to pass by the obstruction, so only the top $170 \mathrm{~m}$ of the hole was logged. However, for the passive experiment, the clamps were removed, and a $1.8-\mathrm{m}$ steel rod was welded onto the bottom of the instrument package. Without the clamps, the maximum diameter of the instrument was $0.08 \mathrm{~m}$, and it was able to easily pass by the obstruction to maximum depth at $900 \mathrm{~m}$. The rod served to keep the geophone upright at the bottom of the well and to help the instrument package penetrate into the debris at the well bottom. The rod and the 
weight of the cable effectively held the geophone securely.

We expected that the well environment would always be substantially quieter than the surface. However, comparison of the signal to noise ratio for selected earthquakes in the two environments reveals that the surface environment appears to be quieter in some cases. This is probably due in part to the different frequency response of the surface and borehole instruments, in part to their response to the predominant sources of noise at the surface and at depth, and in part to unknown effects, such as frequency-dependent attenuation or scattering in the earth. Comparison of spectra for the two environments shows a steep roll-off for the borehole instrument, versus a flat spectrum for the $4.5-\mathrm{Hz}$ surface instrument at frequencies above 15 $\mathrm{Hz}$. Since noise contributes an increasing proportion to the seismogram as frequency increases, we conclude that the well environment is generally quieter at short periods. In addition, the effects of hydrothermal flow and geothermal cracking should be more important at depth than at the surface, where wind and cultural noise effects predominate.

One advantage to the well environment is that phases not normally recorded on the surface may be present. The most important of these should be reflections of upgoing phases off the ground surface, down to the well location. For either $S_{H}$ or $S_{V}$, we also ex pect to see similar reflections off the top of the magma body. These $S$ reflections should have a phase and frequency content similar to those for the downgoing reflections off the free surface. Both $S$ reflections should also be similar to the first $S$ arrival. Thus it may be possible to use the direct $S$ as a matched filter for the phases reflected off the top of the magma chamber. Alternatively, an autocorrelation of the waveform should give a large peak at zero lag and progressively smaller peaks corresponding to arrival times of the reflected phases at successive lag times. Note that $P$ reflections off the magma ought to be rather weak in comparison, since the bulk compressive properties of magma are very similar to those of the surrounding plutonic country rock [Clark, 1966]. Hence magma ought to be relatively transparent to $P$, but opaque to $S$, leading to $S$ reflections. At the present time this work is still in progress, but preliminary results show a number of systematic, later $S$ arrivals on the records, indicating a complex shear wave structure. By contrast, results from the refraction studies indicate a rather simple, deep $P$ wave structure. For the most part, recorded events were located in the south moat of the caldera and further south into the Sierras at distances of $10-20 \mathrm{~km}$.

While differences in surface and borehole waveforms were certainly expected, it is sometimes surprising how great the differences can be. Shown in Figure 8 are the surface and downhole vertical component recordings for an event that occurred on September 27 at 22:59:2.12 UT. This event had local magnitude 1.5 and was located about $18.5 \mathrm{~km}$ south-southeast of the well site in the Sierra Nevada mountains, about $1.5 \mathrm{~km}$ east of Mount Morrison, at $10.3 \mathrm{~km}$ depth. The surface seismogram shows a rather poorly developed, emergent $S$ wave when compared to the impulsive, well-developed $S$ arrival seen on the borehole recording. Note that the $S$ wave ought to be apparent at about $6 \mathrm{~s}$ into the records. A better-developed $S$ arrival is seen on one of the surface horizontal recordings (nearly $S_{H}$, which indicates that at least some shear wave energy is present in the surface waveforms. In fact, preliminary ray tracing suggests that, for this depth and location, the rays should pass through the $S$ wave attenuating region of the caldera defined by Sanders [1984]. Hence the appearance of the surface vertical component waveform in Figure 8 is consistent with shear wave shadowing. It is therefore surprising to see the impulsive character of the borehole $S$ wave arrival, which is just as clear on all three components, and to see shear wave energy on one horizontal component (east-west) of the surface recording. A possible reason for this difference is that shear energy is being removed within the surface layers above the

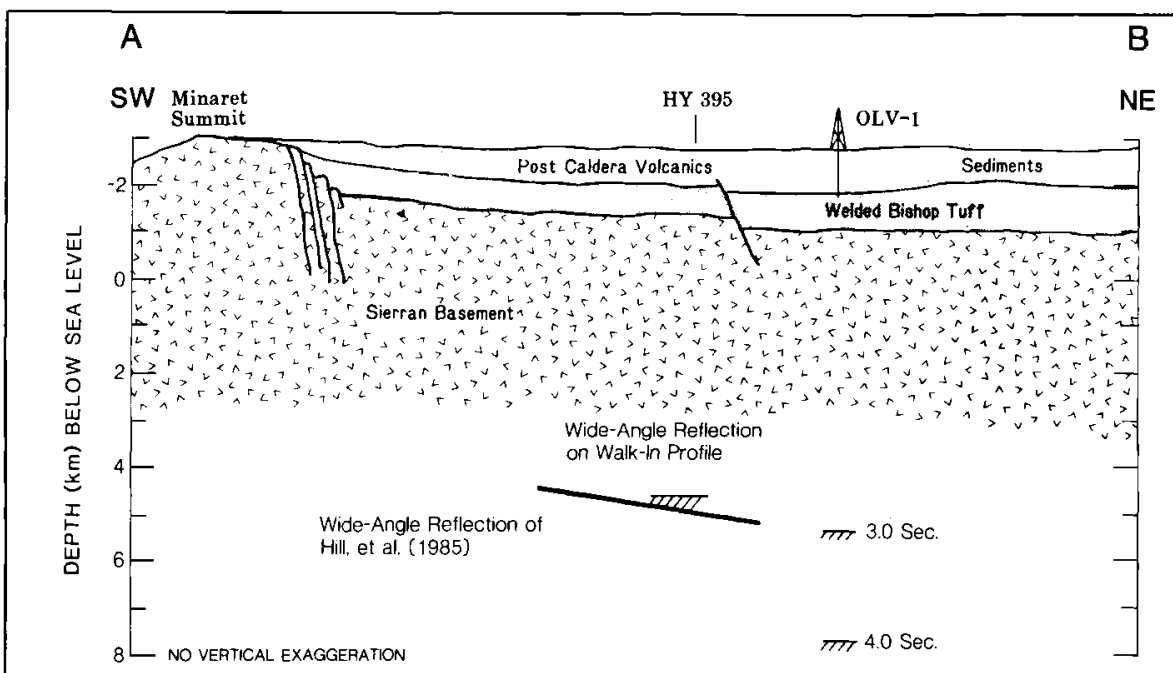

Fig. 6. Summary cross section of structure of northwestern Long Valley caldera along profile A-B of Figure 1. Depth and attitude of contacts between postcaldera volcanics, welded Bishop Tuff, and Sierran Basement based upon interpretation of refraction profiles by Hill et al. [1985]. Depth to deep reflectors found in this program are controlled by velocity structure from refraction interpretation.

borehole site. However, Sanders has examined the possible causes of shear wave shadowing and, on the basis of a large number of raypaths from several hundred earthquakes, concludes that the shadowing effect is not a receiver site effect, at least for surface instruments.

We also made a preliminary examination of about nine other events near the same source-receiver azimuth as the event in Figure 8. Depths for the seven events to the south range from 5 to $10 \mathrm{~km}$, and ranges are from roughly 14 to $22 \mathrm{~km}$. All of these events show substantial differences between the surface and borehole waveforms, but the differences do not appear to be easily rationalized in terms of the simple model developed by Sanders [1984]. Preliminary calculations using simple low-frequency synthetics apparently indicate that some of the differences may stem from $P$ to $S$ conversions upon reflection

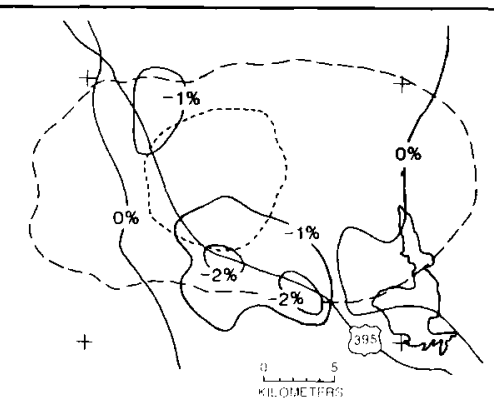

Fig. 7. Contours of lateral variations in $P$ wave velocity in percent within the depth interval from 7 to $9 \mathrm{~km}$ below sea level $(9-11 \mathrm{~km}$ below the caldera floor) determined by geotomographic imaging of earthquake arrival time data. Figure af ter Kissling et al. [1984].

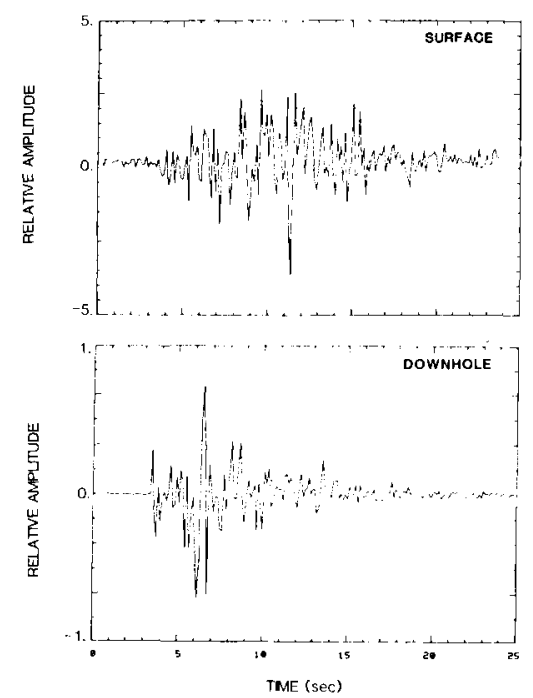

Fig. 8. Comparison of (top) surface and (bottom) downhole vertical component seismograms recorded at the well site. The event was a magnitude 1.5 earthquake on September 27, 1984, at 22:59:02.12 UT. The event was located $18.5 \mathrm{~km}$ south-southeast of the well site at a depth of $10.3 \mathrm{~km}$. Note the well developed $S$ arrival on the downhole instrument at about $6 \mathrm{~s}$, compared to the poorly developed $S$ arrival on the surface instrument. 
off a low-velocity zone at relatively shallow depth. Other differences may be due to reverberations within the upper $900 \mathrm{~m}$. It seems clear that the waveforms are being severely distorted in passing through the southcentral part of the caldera at depths as shallow as $5 \mathrm{~km}$. The ray paths for most of the events we examined pass under the southwest moat and the southern resurgent dome, within $1-3 \mathrm{~km}$ east of the Casa Diablo hot spring area. At the present time we have no clear explanation for the differences between waveforms.

\section{Future Plans}

The success of the recent work in Long Valley has prompted the acceleration of plans to do a great deal more seismic imaging. For example, a new series of reflection profiles is planned, with the first line to be run during the summer of 1985. This profile line will stretch from the OLV-1 well site south across the resurgent dome and terminate against the south wall of the caldera. Funding for this profile will come from the Magma Energy Technology Program. Other profiles will be completed within the following year, with funding to come from DOE, USGS, and NSF The line from Lookout Mountain south will be run during the summer of 1985 as a $P$ profile, and we plan to repeat the line with an $S_{H}$ survey to evaluate this as a technique for locating and defining magma bodies.

The route for the profile will also pass by another well to be drilled on the south end of the resurgent dome during summer 1985 , contingent upon final approval of funding from the office of Basic Energy Sciences. The objective for this well is to be the first permanent borehole crustal observatory in Long Valley. With an anticipated depth of $700 \mathrm{~m}$, the well will be used for a variety of shortterm and longer-term geophysical and geochemical experiments aimed at understanding the cause of the ongoing seismicity, deformation, and hydrothermal activity in the south moat of the caldera. These experiments will include measurement of in situ stress and changes in stress with time; passive recording of south moat earthquakes; observation of temperature, heat flow, and changes with time; a vertical seismic profile; geochemical studies of core obtained, including origin and implications of hydrothermal alteration; observation of long-term pore pressure (strain) changes; and a variety of other experiments. Both the VSP and the $P$ wave profile will provide good control of the seismic structure overlying the hypothesized southern cupola of magma for use in correlating seismic structure with tectonic activity and in comparing with results obtained over the northern cupola. We thus hope to use these techniques to identify the depth to the top of the southern cupola.

Finally, the passive borehole experiment in OLV - 1 has been considerably extended due to a stroke of luck. Original plans called for the borehole instrument to be withdrawn at the end of October. However, a major winter storm made it temporarily impossible to gain access to the site to remove the geophone, and it was decided to leave it in the well until at least spring, if someone could be found to add the instrument to a telemetered network. Fortunately, Alan Ryall at the University of Nevada, Reno, agreed, and telemetry began about the beginning of January. These have so far shown variable signal to noise ratios for the downhole instrument as compared to $1-\mathrm{s}$ surface seismometers mentioned above. At present, none of the events have been located where differences in shear wave attentuation might be observed.

\section{Acknowledgments}

Funding for this project has been provided by the U.S. Department of Energy under contract DE-AC04-76DP00789 to Sandia National Laboratories from the Division of Geothermal and Hydropower Technology and from the Office of Basic Energy Sciences; by the Geothermal Research Program of the U.S. Geological Survey; and by the National Science Foundation. We are grateful to all those who have made this joint project possible.

\section{References}

Achauer, U., L. Greene, J. R. Evans, and H. M. Iyer, Evidence for a low velocity body under Inyo/Mono Craters from the study of Teleseismic $P$ wave travel time residual, Eos Trans. AGU, 65, 116, 1984.

Castle, R. O., J. E. Estrem, and J. C. Savage, Uplift across Long Valley caldera, California, J. Geophys. Res., 89, 11,507-11,516, 1984.

Clark, S. P., Handbook of physical constants, Geol. Soc. Am. Mem. 97, 1966.

Deemer, S., M. C. Humphreys, R. A. Johnson, S. B. Smithson, W. L. Ellsworth, and D. P. Hill, Seismic reflection profiling through the Long Valley Caldera, Eos Trans. AGU, 65, 985, 1984.

Hill, D. P., Structure of Long Valley caldera, California, from a seismic refraction experiment, J. Geophys. Res., 81, 745-753, 1976.

Hill, D. P., E. Kissling, J. H. Luetgert, and U. Kradolfer, Constraints on the upper crustal structure of the Long Valley-Mono Craters volcanic complex, eastern California, from seismic refraction measurements, $J$. Geophys. Res., in press, 1985.

Kissling, E., W. L. Ellsworth and R. S. Cockerham, Three-dimensional structure of the Long Valley Caldera, California region by geotomography, Proceedings of a Conference on Active Tectonic Magmatic Processes Beneath Long Valley Caldera, Eastern California, U.S. Geol. Surv. Open File Rep. $84-939,1984$.

Rundle, J. B., and J. H. Whitcomb, A model for deformation in Long Valley, California, 1980-1983, J. Geophys. Res., 89, 9371-9380, 1984.

Sanders, C. O., Location and configuration of magma bodies beneath Long Valley, California, determined from anomalous earthquake signals, J. Geophys. Res., 89, 8287$8302,1984$.

Steeples, D. W., and H. M. Iyer, Low-velocity zone under Long Valley as determined from teleseismic events, J. Geophys. Res., 81, 849-860, 1976.

Thurber, C. H., Earthquake locations and three-dimensional crustal structure in the Coyote Lake area, central California, J. Geophys. Res., 88, 8226-8236, 1983. 